\title{
Clubes de leitura: a construção de sentidos em situações de leitura colaborativa'
}

\section{Book clubs: the construction of meanings in collaborative reading situations}

Andréa Schmitz-Boccia é especialista em Docência de Língua Portuguesa pelo Instituto Superior de Educação Vera Cruz (ISEVEC), pedagoga e administradora. Trabalha com ensino de línguas estrangeiras há 20 anos. Leitora por vocação, organiza um clube de leitura aberto ao público desde 2008.

Contato: andrea.schmitz@uol.com.br

\section{Resumo}

0 artigo pretende mostrar como a leitura colaborativa, em uma abordagem dialógica, pode contribuir para a formação de hábitos leitores e para a construção mútua de sentidos de leitura. Para isso, observa o funcionamento de um clube de leitura de adultos da Grande São Paulo e reflete sobre a distância que há entre uma proposta de leitura colaborativa e o ensino da literatura na escola, quando realizado de forma inadequada. Em um ambiente que legitima o desejo de ler, em que o "pacto de leitura" contempla a possibilidade de criação de hipóteses interpretativas e em que o "diálogo entre pares" é favorecido em uma relação de interlocução equitativa, os leitores se percebem mais atentos, críticos e conscientes.

Palavras-chave: leitura colaborativa; clube de leitura; abordagem dialógica; escolarização da literatura.

\section{Abstract}

This article aims at showing how collaborative reading, in a dialogical approach, can lead to the development of reading habits and promote a mutual construction of meanings in reading. The observation of a book club for adults in Greater São Paulo evidenced the distance between a collaborative

1. Este artigo baseia-se no trabalho de conclusão de curso da autora, finalizado em 2011 sob orientação do professor Claudio Bazzoni, para o curso de especialização em Docência de Língua Portuguesa do Instituto Superior de Educação Vera Cruz. 
reading proposal and an inadequate literature teaching at school. In an environment where the desire to read is legitimized, in which the "reading pact" contemplates the possibility of creating multiple hypotheses of meaning and in which the "dialog among peers" is favored by equitable communication, the readers perceive themselves as more attentive, critical and conscious.

Keywords: collaborative reading; book club; dialogical approach; literature at school.

Ora, quem quer emancipar um homem deve interrogá-lo à maneira dos homens e não à maneira dos sábios, para instruir-se a si próprio e não para instruir um outro.

Jacques Rancière

\section{Introdução}

Este artigo tem o objetivo de analisar o papel dos "clubes de leitura" para a construção de sentidos de leitura e, consequentemente, para a formação de leitores autônomos. 0 leitor autônomo é aquele que coopera com o texto, transcende o literal e embrenha-se no não dito. Sua interlocução com o texto é genuína. Ele não vê o texto como fechado para o mundo, já que sabe que é preciso contextualizá-lo sempre. Mas, enquanto o tem nas mãos, busca apropriar-se dele, em uma atitude de atenção e colaboração.

A ideia da pesquisa emergiu de estudos teóricos sobre a leitura e o ser leitor, realizados no curso de especialização em docência de Língua Portuguesa², e da experiência prática desta estudantepesquisadora na organização de um clube de leitura³. Ambicionase, com isso, mostrar como a leitura colaborativa e solidária, em uma abordagem dialógica, pode fazer suscitar no leitor um interesse mais profundo e autônomo.

Clubes de leitura, círculos de leitura, tertúlias literárias e grupos de leitura são algumas das nomenclaturas que identificam espaços de leitura e discussão de livros. Não seria possível generalizar as regras de funcionamento dos inúmeros clubes de leitura existentes, uma vez que são produtos de agregamentos sociais com necessidades ou propósitos próprios e até, não raramente, únicos. No entanto, em comparação com a leitura e o estudo literário escolarizados - normalmente visando à leitura de textos canônicos, guiados muitas vezes por roteiros de compreensão,
2. Especialização realizada no ISE Vera Cruz, sob coordenação da Professora Maria José Nóbrega, de fevereiro de 2010 a julho de 2011.

3. Desde outubro de 2008, a autora deste artigo organiza um clube de leitura presencial, cuja experiência pode ser em parte visualizada no blog www.nossoclubedeleitura.blogspot.com. 
ou com o objetivo de classificar as obras em períodos ou estilos - os clubes de leitura buscam, em geral, a fruição da leitura e a discussão de aspectos relevantes para o grupo.

Levando-se em consideração o estudo de diferentes teorias sobre a leitura e o significado de ser leitor e ensaios sobre a importância sociocultural da leitura, surgiram duas perguntas, objetivos desta investigação:

1. qual seria a importância de espaços não tradicionais, como os clubes de leitura, para a formação de hábitos leitores?

2. em que medida o clube de leitura contribui para a elaboração individual de sentidos de leitura de uma dada obra?

Em um segundo plano, questionou-se, ainda, em que aspectos essa abordagem se diferencia da literatura escolarizada.

Assim, este artigo está dividido em três tópicos: o primeiro trata das concepções de leitura que serviram de base para esta pesquisa e também flerta com a ideia do diálogo como instigador da compreensão leitora; o segundo tópico aborda parte das análises realizadas a partir dos dados colhidos para a pesquisa; por fim, buscou-se sintetizar algumas das considerações finais a que se chegou no decorrer da pesquisa.

\section{A leitura, o ser leitor e a relevância do diálogo para a compreensão de leitura}

São tantas as possibilidades de construção dos significados no ato de ler quanto são diversos os modos como nos posicionamos diante do mundo. Em cada momento de leitura, nosso olhar foca, no texto, aspectos diferentes. Enxergamos e sentimos cada texto de acordo com o ponto de vista já vivido ou pretendido, e de acordo com as expectativas em relação ao que lemos e ao que vamos ler. Assim, a leitura de um mesmo livro em dois momentos distintos da vida provavelmente trará sentidos e significados diversos - tanto quanto tivermos transformado nossa perspectiva sobre o assunto abordado. Nossas vivências interferem na leitura e as inferências, por sua vez, tomam vida em nós de forma diferente, dependendo das circunstâncias de leitura do texto e das experiências pessoais.

Segundo Olson (1997), qualquer leitura comprometida deveria contemplar a ideia de que há nos textos escritos mais do que eles aparentemente dizem. Seria importante pensar na interpretação 
além do léxico e da gramática, mas também no contexto da escrita, no autor e no seu possível público leitor, o que Olson chamou de recuperação da força ilocucionária. Para ele:

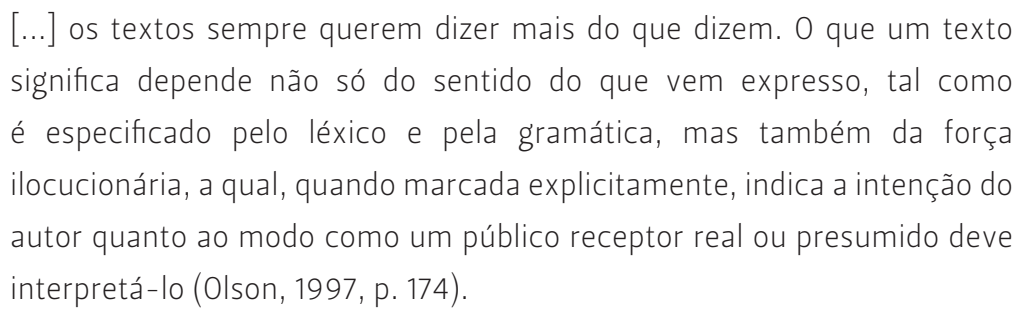

A força ilocucionária, portanto, é recuperada, ainda que pelo menos em parte, por meio da leitura atenta e do reconhecimento pelo leitor de "pistas sutis, textuais ou contextuais" (Olson, 1997, p. 174) que fazem com que ele decida como o texto deve ser entendido.

De modo semelhante, Umberto Eco, em sua obra Lector in Fabula, expressa a necessidade de atualização, no momento da leitura, do "não dito" do texto (p. 36). Para isso, é preciso que haja um trabalho consciente e ativo por parte do leitor, por meio de movimentos cooperativos e inferenciais, tendo-se em mente, antes de tudo, os deveres filológicos do leitor para com o texto. Eco afirma que "todo texto quer que alguém o ajude a funcionar" (p. 37). Sendo o texto "uma máquina preguiçosa", ele "vive da valorização de sentido que o destinatário ali introduziu" (p. 37).

A leitura propriamente dita poderia ser pensada como a valorização de sentido de um texto, partindo-se do pressuposto de que há nos textos escritos sempre mais do que eles aparentemente nos mostram. 0 leitor, por sua vez, seria aquele que ajuda 0 texto a funcionar; quem lhe dá sentido, tarefa que pressupõe competências para que seja exercida de forma plena e autêntica.

Portanto, ao que parece, a leitura poderia ser tida como a constituição de sentido de um texto pelo leitor, em sua complexidade cultural e histórica, partindo-se do pressuposto de que os textos escritos (narrativos) não se fecham em si mesmos; ao contrário, dão indícios (mais ou menos certos, dependendo do conteúdo programado pelo narrador) que permitem a sua decifração. A leitura afronta e manipula; cria vida no texto.

O leitor, em sua complexidade psicológica, social e históricocultural, ajuda o texto a funcionar, institui-lhe um sentido, em uma atitude cooperativa e inferencial, tarefa que envolve um jogo interativo de sucessivas hipóteses interpretativas. 0 leitor 
real concretiza a leitura atualizando o texto culturalmente e se atualizando nele, posicionando o texto em sua realidade e posicionando-se perante ele.

Tendo em vista as concepções da leitura e do ser leitor a que aqui chegamos, é certo que o ensino da leitura deva tomar a construção de sentidos, em toda sua complexidade, como sua pedra fundamental. 0 envolvimento do aluno deve ser a base para a transformação do ensino da leitura na escola. Compreensão e fruição devem andar juntas.

É preciso que haja, entre outros fatores, uma disposição pessoal e uma atitude interessada por parte do leitor. Talvez essa seja a chave inicial (e talvez a mais intrincada) para o trabalho escolar de leitura: suscitar o interesse - tanto do aluno como do próprio professor.

Um leitor proficiente e autônomo é capaz de aprender a partir dos textos, apropriar-se deles pelas relações de sentido, avaliando consistências e inferindo significados e efeitos. Assim, parece estar clara a necessidade de tornar o aluno autônomo e consciente, capaz de escolher suas próprias estratégias de leitura.

A prática percebida com a organização do clube de leitura mostrou que os leitores adultos participantes se utilizam de diversas estratégias e que são, no momento dos encontros de discussão da leitura, compartilhadas com os demais integrantes. Para poder compreender melhor o que ocorre na prática do clube de leitura em questão, três abordagens foram utilizadas: dos pesquisadores Jover-Faleiros (2009), Flecha (1998) e Hébert (2008).

Para Jover-Faleiros ${ }^{4}$, em sua pesquisa baseada em reuniões de leitura de textos literários com estudantes de graduação em Letras, a valorização das impressões do leitor autoriza que novas interpretações sejam sempre possíveis e legitima a experiência de fruição estética do texto, que liberta e permite que o leitor renove sua percepção de mundo, com uma construção própria de sentidos do que leu.

Jover-Faleiros discorre também sobre a relevância das verbalizações orais para a construção de sentidos de leitura. Assim como Flecha ${ }^{5}$ (1998), que cita a aprendizagem dialógica como modo de leitura colaborativa. Ao descrever e analisar tertúlias literárias realizadas por adultos em um bairro operário de Barcelona, na Espanha, ele é enfático ao apontar a horizontalidade
4. A pesquisadora brasileira Rita Jover-Faleiros organizou junto a alunos do primeiro ano da habilitação em língua e literatura francesa da FFLCH da USP, em 2008, um grupo de leitura para o qual foi proposta a leitura de prefácios de autores que dialogavam com os textos que os alunos leriam no curso de Introdução à Literatura Francesa. A experiência fez parte de sua tese de doutorado do programa de Pós-graduação em Língua e Literatura Francesa do Departamento de Letras Modernas da Faculdade de Filosofia, Letras e Ciências Humans da Universidade de São Paulo, com o título: "Didática da leitura na formação em FLE: em busca de leitores". (Jover-Faleiros, 2009).

5. Ramón Flecha, professor da Universidade de Barcelona e autor do livro Compartiendo palabras: el aprendizaje de las personas adultas a través del diálogo (1998), em que descreve os princípios da aprendizagem dialógica. 
como situação ideal de fala. No modelo dialógico, como proposto por Flecha, o objetivo não é se chegar a uma opinião homogênea.

0 diálogo igualitário, segundo ele, valida as falas de acordo com os argumentos e não através de uma hierarquia de poder. Ele "potencializa, em vez de anular, a reflexão de cada pessoa" (Flecha, 1998, p. 45). Em relações igualitárias (em contextos horizontais e equitativos, em que não há relação explícita de poder), o diálogo tende a caminhar rumo à superação de desigualdades, ainda que o contexto de comunicação social seja real, portanto não neutro, e algumas vozes exerçam maior influência que outras.

De um modo semelhante, a pesquisadora Hébert (2008) ${ }^{6}$, que realizou investigações sobre estratégias de leitura utilizadas por crianças em círculos de literatura sem a intervenção de um professor, em uma escola de ensino fundamental canadense, acredita no diálogo entre pares como uma forma efetiva de aprendizagem. 0 diálogo em um contexto horizontal, segundo ela, se mostrou um modo eficiente para que os alunos fossem expostos a uma ampla gama de ideias, modos de leitura e estratégias, que os fizeram superar uma compreensão simplista ou literal.

A partir dessas abordagens buscou-se compreender os efeitos que ocorrem no clube de leitura. Seria o diálogo entre pares realmente um incitador da autonomia do leitor? De que forma o diálogo colaborativo contribui para a compreensão individual de leitura? Como a leitura colaborativa é percebida pelos leitores participantes do clube de leitura?

\section{Mudanças de hábitos leitores em situações de leitura colaborativa}

A coleta de dados para esta pesquisa foi realizada por meio de questionários respondidos pelos participantes do "Nosso Clube de Leitura", um grupo aberto ao público e formado por adultos de formações profissionais variadas que se reúnem mensalmente para debater obras literárias. A partir de uma seleção prévia de livros, realizada pelas duas organizadoras do clube de leitura, os participantes elegem (por meio de votação) o livro que será lido por todos em cada mês.

Ainda que o grupo funcione em um contexto não escolar e seja formado por adultos, pensou-se que a análise dos resultados poderia levantar aspectos interessantes sobre a leitura
6. Manon Hébert é pesquisadora na Faculté des Sciences de l'Education do Départment de Didactique da Université de Montreal e investigou, entre outras questões, as estratégias de leitura, modos de colaboração e tipos de interação ocorridas em círculos de leitura formados por alunos de uma escola de ensino fundamental II, sem a intervenção de um professor. A investigação faz parte da tese: Co-elaboration of meaning in peer-led literature circles in secondary school: the interplay between reading modes, quality of talk and collaboration modes (2008) 
colaborativa, em que o diálogo entre pares seja capaz de promover uma interlocução real com as obras literárias e com os sentidos de leitura também nas instituições escolares.

Pretendeu-se buscar em dois momentos distintos (antes e depois do encontro do clube de leitura), aspectos que pudessem deixar transparecer uma possível mudança de hábitos leitores gerada pela participação no clube de leitura. A proposta de elaboração de questionários foi a que se pensou mais adequada para esse propósito.

No questionário distribuído antes do encontro do clube de leitura, os participantes foram convidados a identificar até que ponto percebiam os encontros do clube de leitura, de um modo geral, como agentes de mudança na maneira de ler textos literários. A pergunta, de resposta aberta, foi: "A participação no clube de leitura mudou sua maneira de ler textos literários? Em que aspectos?".

A totalidade dos respondentes afirmou perceber uma mudança no hábito e na qualidade da leitura. As respostas trazem à tona impressões diversas, mas convergentes no sentido da existência de um maior comprometimento com a leitura e com a construção interpretativa, gerados pelo compromisso com o grupo.

Compromisso que não é imposto, uma vez que a participação nos encontros é sempre livre, e não envolve resultados diretos, a não ser a própria fruição da leitura e o encontro com pessoas que partilham de interesse pela leitura.

Observam-se, pelas respostas dadas, alguns aspectos comuns que podem identificar a mudança de hábitos leitores em função da participação no clube de leitura. Uma possível categorização foi pensada em quatro níveis: (a) comprometimento com a leitura, (b) ampliação de repertório, (c) expectativa de construção de novos sentidos e (d) contexto da obra.

0 comprometimento com a leitura, ou uma leitura mais séria, atenta, consciente e crítica, foi citado, ainda que de forma indireta, por oito dos nove participantes.

Segundo Flecha (1998, p. 33), o melhor instrumento cognitivo para desenvolver-se na sociedade atual passa pela capacidade de seleção e processamento de informações, estratégia presente na fala de um dos leitores: "Agora marco as frases e as partes do livro que quero comentar com o grupo. Desenvolvi um tipo de leitura mais profunda e atenta". 
É possível notar, como também observou Jover-Faleiros (2009) em sua pesquisa, que o leitor busca "empreender uma leitura minuciosa, sublinhada" tentando apropriar-se "fisicamente do texto escrito" (p. 123).

Como explicar que a maior seriedade e aprofundamento da leitura, destacada pelos leitores, ocorra em função dos encontros do clube de leitura, já que não se trata de um pré-requisito para frequentar as rodas de conversa? A necessidade de expor as opiniões em público pode levar a uma maior dedicação individual. A existência do encontro e a expectativa do diálogo com o grupo acabam suscitando uma vontade e uma motivação que se fazem presentes sem que haja uma formalização para um preparo prévio.

0 clube de leitura, representado como um grupo social, pode legitimar o desejo de ler de cada um. Desejo que já existia antes da participação individual no clube, mas que se tornava ato solitário e sem respaldo social. Com o espaço do diálogo propiciado pelo clube de leitura, torna-se possível e passível o encontro com outros desejos de conhecer o mundo por meio da leitura. Recorrendo a Petit:
[...] a leitura pode reforçar a autonomia, mas o fato de alguém se entregar a ela já pressupõe uma certa autonomia. A leitura ajuda a pessoa a se construir, mas pressupõe, talvez, que ela já tenha se construído o suficiente e que suporte ficar a sós, confrontada consigo mesma (Petit, 2008, p. 134).

0 respeito entre os participantes, a possibilidade de legitimar a própria leitura e a receptividade do grupo podem trazer como consequência o compromisso com o objetivo maior: uma melhor compreensão da obra lida.

0 reforço à autonomia, propiciado pelo grupo, fica claro na resposta de um dos leitores:

[...] ele [o clube de leitura] me proporcionou o contato com a literatura que tinha ficado perdido lá no colegial. E quanto mais leio, mais crítica vou ficando, já não me conformo com qualquer texto.

0 grupo, criado inicialmente apenas para compartilhar as leituras, acaba por valorizar e legitimar a função da leitura em nossas vidas. Funciona, nesse caso, como um contraponto à realidade corrente e "corrida" da humanidade. Autoriza o fictício, não como fuga do real, mas como uma alternativa à condição humana. Um contato que, como afirmou o leitor, existiu em algum momento de sua vida escolar, perdeu-se por razões diversas e, graças ao apoio de uma coletividade, é reencontrado. 
Paradoxalmente, o grupo, tanto pela forma como é organizado e pelas escolhas dos livros a serem lidos, como pelos sujeitos que dele participam, apesar de ser um livre espaço de reunião, traz em alguma parte de sua constituição social uma ideia de compulsoriedade. Uma pré-definição da data para a discussão do livro parece tornar a leitura algo compulsório, que deve ser planejado. Diferentemente do que se vê ocorrer com frequência no ambiente escolar, a diretividade no clube de leitura não carrega uma conotação negativa, já que a participação é fruto do livrearbítrio dos participantes. No caso do grupo em questão, a leitura não é nunca objeto de controle ou alvo de algum tipo de avaliação. A compulsoriedade talvez signifique apenas uma meta formal e concreta necessária para que a leitura seja realizada com mais comprometimento e seriedade, com a ideia de ser um "pacto de leitura".

A possibilidade de ampliação do repertório, segunda categoria pensada para esta análise, se vê presente nas respostas que mencionaram a seleção dos livros como um dos aspectos responsáveis pela mudança nos hábitos de leitura. Quatro dos nove respondentes fazem menção, ainda que indiretamente, à escolha dos livros. Isso também faz pensar por que razão a compulsoriedade na escola é muitas vezes vista como vilã, o que não ocorre no clube.

Segundo Jover-Faleiros (2009, p. 136),

\footnotetext{
[...] uma das questões recorrentes que se colocam quanto à leitura literária em sala de aula é seu caráter obrigatório, o que configuraria uma situação em que se lê para estudar, distanciando-se de uma representação da leitura literária "espontânea"[...]
}

Além disso, ainda que uma seleção de quatro ou cinco livros por mês seja realizada previamente pelas organizadoras do clube de leitura, a escolha efetiva do livro de cada mês ocorre por votação. Os critérios utilizados para a seleção prévia são movidos pela opinião da crítica especializada ou por listas de premiações literárias, mas também pela percepção do desejo dos participantes, ou de interesses suscitados por leituras já realizadas pelo grupo. A participação dos leitores nas escolhas dos livros é notadamente importante, pois democratiza as decisões, legitimando o "pacto de leitura".

O caráter diretivo está de certo modo presente, em função da pré-seleção mensal, considerada relevante, pois desafia o grupo à 
leitura de livros considerados mais "difíceis" e que, como clássicos, fazem parte de nossa formação sociocultural. Sobre o assunto, uma leitora escreveu: "[...] agora sou mais aberta a ler textos que em outros momentos não teria escolhido".

Ora, o fato de nos obrigarmos a ler livros que não escolheríamos é importante, pois, com isso, saímos de uma zona de conforto. Podemos tender a ler apenas o que nos agrada, ou histórias que confirmem nosso próprio modo de pensar. Com uma escolha nem sempre dependente de nossa vontade, é possível ousar e experimentar autores ou histórias que transcendam nossa própria experiência. Como afirma Jouve (2002), quando confrontados com a diferença, os leitores podem se redescobrir. "O interesse do texto lido não vem mais então daquilo que reconhecemos de nós mesmos nele, mas daquilo que aprendemos de nós mesmos nele" (p. 131). A apropriação de uma obra que nos incomoda pode ser enriquecedora ao ampliar nosso conhecimento de mundo.

Por outro lado, a liberdade e a independência presentes na participação voluntária dos leitores no clube de leitura manifestam-se em muitos aspectos: o direito à escolha dos livros (ainda que haja uma indicação prévia), a possibilidade de participar em todos os meses ou não, a eventual recusa em ler determinado livro, a possibilidade de pular trechos ou escolher as passagens que mais tenham lhe tocado e de realizar interpretações totalmente diferentes da maioria do grupo.

A terceira categoria que indica mudança de hábitos leitores, percebida na análise das respostas aos questionários, diz respeito à expectativa de compartilhar outros olhares interpretativos.

A possibilidade de debater o conteúdo e a forma de uma obra literária vai ao encontro da natureza dialógica da interpretação literária e respeita o que é intrínseco ao texto literário. A pesquisadora canadense Hébert (2008, p. 29) afirma que a interpretação nunca é estanque, e resulta da interação simultânea de vários modos de leitura. Modos que incluem uma atitude interpretativa chamada de "pública" (relativa à análise da forma estrutural e informativa do texto) e outra, antagônica, mas complementar, chamada de "privada" (relativa ao modo estético, de significado pessoal do texto lido), que é uma atitude ainda rejeitada, conforme a pesquisadora, por muitos professores que duvidam de sua eficácia. Segundo ela, as escolas deveriam também perseguir esse último tipo de modo de leitura como o mais efetivo para ler ficção e poesia, rejeitando a racionalização como único modo de ler. Sua pesquisa se baseia em círculos literários 
existentes em algumas escolas canadenses, em que a leitura é centrada no aluno e sem a presença do professor como autoridade máxima, e que fazem uso da atitude privada como modo de construção da compreensão do texto.

Essas considerações são corroboradas pelas opiniões dos participantes do clube de leitura:

\footnotetext{
Invariavelmente o encontro no clube de leitura traz uma nova perspectiva sobre a leitura realizada. É impressionante a diversidade de entendimentos que um mesmo texto propicia. Dessa forma há sempre uma expectativa, um desejo pelo encontro, para conhecer outros olhares sobre o texto lido.
}

A verbalização dos processos de compreensão é produtiva, afirma Hébert (2008, pp. 32-33), desde que os sujeitos estejam verdadeiramente engajados na argumentação e o conflito envolva um objetivo comum de resolução de problemas.

Para Jover-Faleiros (2009, pp. 132-134), a experiência de mundo (incluindo o conhecimento enciclopédico e o repertório de leituras anteriores) é acionada no momento da verbalização da interpretação.

A aproximação das leituras pessoais, nos encontros do clube de leitura, é realizada por meio de um diálogo em que as verbalizações orais ocorrem de forma livre, diferentemente do que ocorre na escola em que existem roteiros e questionários que frequentemente direcionam a interpretação. Jover-Faleiros (2009) afirma que o momento das verbalizações orais é o momento mais interessante dos encontros-objetos de sua pesquisa-ação: "um momento ímpar de interação entre pares que negociam diferentes sentidos sobre um mesmo texto [...]" (p. 82), no que ela chama de "torneio argumentativo".

No clube de leitura, as leituras nem sempre são condizentes com as leituras manifestadas pela crítica especializada. As verbalizações dos participantes incorporam, também, as relações afetivas estabelecidas com o texto. A escuta do outro transforma as impressões iniciais da leitura realizada antes do encontro e as falas ouvidas tornam-se constitutivas de uma nova compreensão. Assim, o diálogo e a discussão sobre a leitura, atividade central nas rodas de conversa do clube, inevitavelmente, fazem com que a compreensão pessoal de cada um se modifique, ou se amplie, ou se confirme. As posições iniciais se reelaboram durante e após cada encontro. A fala do outro repercute em cada um dos presentes durante o debate, e continua repercutindo também após 
o encontro. Um leitor afirmou:

Desfruto muito mais da literatura. Durante os encontros descubro frases dos livros [em] que não tinha reparado e somo as visões e as reflexões do grupo às minhas. É muito enriquecedor em diferentes aspectos.

Se, conforme afirma Jover-Faleiros (2009, p. 126), "alguns (leitores empíricos) preenchem mais as condições para fazer o texto, essa 'máquina preguiçosa' (Eco, 1985), funcionar, e outros, menos", o 'torneio argumentativo' realizado nos encontros do clube de leitura permite que as atualizações individuais do texto evoquem em cada um dos participantes pistas e novas hipóteses do não-dito pelo autor. A possibilidade de encontrar outros leitores cria, em cada participante, expectativas acerca de outras possíveis chaves de interpretação, que possam vir a resolver seus próprios problemas de leitura'.

Flecha (1998, p. 14), ao conceituar o diálogo igualitário, fala sobre como, em um contexto horizontal, as ideias são consideradas não pelas posições de poder ocupadas pelos sujeitos, mas pela validade de seus argumentos. Por essa razão, talvez, os participantes do clube de leitura sintam-se encorajados a expor e aprofundar a leitura, melhorando a compreensão do texto, com o objetivo de participar do jogo argumentativo. Um leitor explica:

Outro aspecto é o fato de ler o livro já elaborando a minha opinião e considerações para expor de maneira clara para o entendimento dos demais. Quando temos isso em mente a elaboração sai do nível sentimental e sensorial e vai para um nível racional, enriquecendo a leitura.

É perceptível a importância que ele dedica à leitura e ao momento do encontro, em que terá a oportunidade de manifestar seu ponto de vista pela argumentação. 0 leitor se prepara, sabe que sua opinião vai, efetivamente, ser considerada na construção da leitura. Uma leitura rasa não basta, não é suficiente para ingressar no jogo argumentativo de cada encontro. 0 leitor de um clube de leitura tacitamente sente-se desafiado a ir além do sensorial, talvez porque seus argumentos convincentes valham tanto quanto a leitura do texto. Percebe que, como afirma Flecha (1998), a linguagem - a representação do que leu - ocupa um lugar fundamental como meio de entendimento.

Os encontros do clube de leitura contemplam as interpretações pessoais de todos os presentes. 0 contexto social do diálogo é real, já que alguns se expõem mais do que outros. Mas os comentários não são classificados como melhores ou piores, apenas diferentes. 
É sabido pelos participantes que o convencimento só pode ser conseguido por meio da argumentação. 0 que explica, de certa forma, a necessidade que alguns leitores sentem de se preparar previamente, elaborando, como faz o leitor citado, suas opiniões e considerações de modo claro visando a expô-las aos demais participantes.

Além disso, a comunicação oral que ocorre nos encontros leva em conta não apenas o ser ouvido, mas também o outro lado, o da escuta, tão importante quanto o primeiro. Há colaboração e enriquecimento mútuo. 0 fato de ouvir e ser ouvido aumenta a autoconfiança em falar sobre textos literários.

Embora não haja a figura de um especialista nos encontros, é interessante notar que a crítica e os estudos literários são, ainda que indiretamente, trazidos ao debate. Seja por intermédio de outras leituras realizadas visando a complementar a interpretação da obra (aqui incluindo-se também pesquisas na internet, ainda que em sites não literários) seja por intermédio de vivências individuais anteriores com outras obras ou estudos literários, os conhecimentos prévios de cada participante são mobilizados pelo discurso individual. 0 grupo (e cada participante individualmente) apodera-se dos discursos ouvidos, cada um a seu modo. Ainda que as inferências sejam estratégias realizadas individualmente, o diálogo do grupo (ou o 'torneio argumentativo', como exposto por Jover-Faleiros) permite que os discursos e, consequentemente, as informações e conhecimentos individuais de que vêm recheados, sejam compartilhados. 0 discurso dos especialistas, contudo, quando chega ao encontro, não o faz para desautorizar a fala dos participantes, mas como se fosse mais uma voz, que pode, ou não, ser aceita como um argumento válido.

O convencimento pela posição argumentativa é mais eloquente, mais enriquecedor para o crescimento pessoal, do que o convencimento pela posição de poder. Afinal,

\footnotetext{
[...] ao dar forma a um objeto, um acontecimento ou um caráter, o escritor não faz a imposição de uma tese, mas incita o leitor a formulá-la: em vez de impor, ele propõe, deixando, portanto, seu leitor livre ao mesmo tempo em que o incita a se tornar mais ativo (Todorov, 2010, p. 78).
}

A quarta categoria referenciada na análise das respostas à pergunta relativa às mudanças no hábito de ler relaciona-se com um maior envolvimento com o contexto do livro, as intenções do autor e o contexto sócio-histórico em que a obra tenha sido escrita e/ou narrada, envolvendo um processo autônomo de pesquisa e estudo. 
Os leitores buscam, individualmente, o aspecto da contextualização da obra sobre o qual desejam se aprofundar, cada um a seu modo. Essa busca é natural, ou seja, não é um pré-requisito para a participação nos encontros do clube de leitura. Segundo Cosson (2009, pp. 85-91), existe um número "teoricamente ilimitado" de contextos possíveis de serem explorados. Dentre essas possibilidades de se abordar o texto, o autor destaca a contextualização teórica (ideias que sustentam ou estão encenadas na obra), histórica (que inclui a contextualização biográfica ou editorial da obra), estilística (ligada às características dos períodos literários tradicionalmente abstraídos e ensinados na escola), poética (estruturação ou composição da obra), crítica (recepção do texto literário), presentificadora (correspondência da obra com o momento presente da leitura) e temática (repercussão de um tema na obra).

Pode-se afirmar que o envolvimento com algum dos contextos do livro foi citado por quatro dos nove respondentes como modos percebidos de transformação no hábito de ler, com a participação no clube de leitura. 0 leitor se vê levado a ir além do sentido da obra. Ele se percebe um observador do estilo em que o texto foi escrito, estabelecendo comparações com outros autores já lidos: "Também presto mais atenção no estilo de escrever do autor, estabelecendo comparações com outros".

Ao mesmo tempo em que a leitura de qualquer texto é sempre inédita, pois resultado de um encontro entre o livro e o leitor (Jouve, 2002, p. 102), ela é também sempre "[...] uma leitura comparativa, contato do livro com outros livros" (Goulemot, 2009, p. 112).

A conversa que é mantida durante o encontro do clube de leitura propicia, ainda, maiores chances de que haja participação e contemplação da leitura. Com Jouve (2002, p. 111), concluo que o leitor ganha uma atitude mais contemplativa da leitura, pois busca chegar a uma visão de mundo que não é a de seu universo cultural cotidiano.

\section{Considerações finais}

Este artigo mostrou que a abordagem dialógica utilizada no clube de leitura pode ser um dos caminhos a ser adotado para tornar mais significativa a leitura de textos literários e aumentar o envolvimento dos leitores com os livros. 0 diálogo entre pares, em grupos em que a relação entre os interlocutores é equitativa, 
pode ser um percurso eficaz para a formação da autonomia de estudantes que começam a envolver-se com o texto literário, ainda que a inclusão do diálogo não baste por si só, já que deveria vir acompanhada de outras mudanças importantes em aspectos que estão historicamente presentes na escola, como a necessidade de avaliação constante e o controle excessivo da atividade de leitura.

Foi possível perceber, no clube de leitura, um maior comprometimento do leitor com a leitura, e de cada leitor com o grupo. No "pacto de leitura" entre os participantes, não há uma autoridade especialista única. Todos são autorizados a ter convicções e dúvidas a respeito do livro, e a verbalizar as opiniões. Em outras palavras, buscar argumentos e participar do jogo interpretativo é tão importante quanto ler o livro. Apesar da horizontalidade das relações, percebeu-se também a importância da mediação organizadora que orienta as atividades do grupo. Um grau mínimo de diretividade é importante para o grupo e esperado pelos participantes, tanto no estabelecimento e manutenção de uma normatização geral, como na promoção de um repertório ampliado de leituras, não imposto, mas sugerido.

Além disso, a discussão colaborativa sobre a leitura que ocorre nos encontros contribui para o enriquecimento da construção individual de sentidos de leitura, na medida em que se compartilha do olhar interpretativo do outro. 0 "torneio argumentativo" faz com que a compreensão do livro ganhe complexidade e amplitude, pois não se resume mais à interpretação solitária. A leitura torna-se significativa o tempo todo, já que a percepção da obra é valorizada tanto quanto sua forma e conteúdo.

A contextualização também se torna mais livre. 0 leitor autônomo busca, a partir de suas necessidades individuais, o tipo de contexto que lhe faz falta no momento da leitura. A necessidade se dá pela própria leitura, e da curiosidade que esta lhe suscita. No encontro do clube de leitura, invariavelmente, é possível aprender. Seja com o olhar interpretativo alheio, com a história pessoal de cada participante ou com a rememoração que os pares fazem de outros livros e leituras.

Uma escolarização adequada da literatura não pode afastar-se do contexto social da leitura. Para formar leitores competentes e autônomos, que se apropriem dos textos e que saibam como inferir e avaliar não apenas o conhecimento escolar, mas o mundo em que vivem, é fundamental valorizar a atitude privada e estética da leitura, contribuindo para a formação de hábitos leitores, 
legitimando a cumplicidade entre leitura e leitores.

É possível mudar o modo como a literatura é tratada e discutida.

Em um ambiente que legitima o desejo de ler, os leitores se percebem mais atentos, críticos e conscientes. No diálogo entre pares, como ocorre no clube de leitura, os sentidos são construídos individualmente, reelaborados coletivamente, e novamente reconstruídos de modo privado; não se fecham, permanecem abertos a novas possibilidades, a novas argumentações, clamam por novos diálogos e por novas leituras.

Quando as perguntas nascem de uma indagação e de uma curiosidade autênticas, resultados de uma tensão do desejo de conhecer, o interesse real aparece, provido por uma vontade autônoma. Ao contrário do que ocorre quando a escolarização da literatura é feita inadequadamente, a interpretação da leitura deve ser conquistada, e não concedida. A contextualização e o significado de uma obra são plurais e devem contemplar a criação de hipóteses, em uma interlocução genuína com o texto.

\section{REFERÊNCIAS}

COSSON, Rildo. Letramento literário: teoria e prática. São Paulo: Contexto, 2009.

ECO, Umberto. Lector in fabula. São Paulo: Perspectiva, 1985.

FLECHA, Ramón. Compartiendo palabras: el aprendizaje de las personas adultas a través del diálogo. Barcelona: Paidós, 1998.

GOULEMOT, Jean Marie. Da leitura como produção de sentidos. In: CHARTIER, Roger. Práticas da leitura. São Paulo: Estação Liberdade, 2009, p. 107-116.

HÉBERT, Manon. Co-elaboration of meaning in peer-led literature circles in secondary school: the interplay between reading modes, quality of talk and collaboration modes. Montreal: Université de Montreal, 2008. 
JOVER-FALEIROS, Rita. Didática da leitura na formação em FLE: em busca de leitores. 2009. Tese (Doutorado em Língua e Literatura Francesa) Faculdade de Filosofia, Letras e Ciências Humanas, Universidade de São Paulo, 2009.

JOUVE, Vincent. A leitura. São Paulo: Editora UNESP, 2002.

OLSON, David. O mundo no papel. São Paulo: Ática, 1997.

PETIT, Michèle. Os jovens e a leitura: uma nova perspectiva. São Paulo: Editora 34, 2008.

RANCIÈRE, Jacques. O mestre ignorante: cinco lições sobre a emancipação intelectual. Belo Horizonte: Autêntica, 2007.

TODOROV, Tzvetan. A literatura em perigo. Rio de Janeiro: DIFEL, 2010.

Recebido em janeiro de 2012 Aprovado em março de 2012 